\title{
HIGH RESOLUTION GLOBAL OCEAN CIRCULATION SIMULATION OF THE EARLY EOCENE: COMPARISON WITH FORAMINIFERAL ISOTOPE PALEOTEMPERATURES
}

\author{
BICE, Karen L., Earth System Science Center, Penn State University, University \\ Park, PA 16802 U. S. A., email: kbice@essc.psu.edu
}

Compared to Earth's present climate, Early Eocene global temperatures were warmer, the meridional surface temperature gradient was reduced, and deep ocean water temperatures were $8^{\circ}$ to $12^{\circ} \mathrm{C}$ warmer than the present-day. The change to the warm conditions of the Early Eocene from the cooler climate of the Paleocene was fairly abrupt. Increased atmospheric $\mathrm{CO}_{2}$ and a dramatic change in global ocean circulation patterns have been cited as likely causes of these warmer conditions. An extensive suite of global ocean circulation simulations has been performed using boundary conditions appropriate for the Early Eocene (55 Ma). Simulated warming at depth ( $2-5 \mathrm{~km}$ water depth) occurs as a result of changing only ocean basin configuration from that of the present-day to a reconstruction of the Early Eocene. Additional warming at depth results from increased atmospheric $\mathrm{CO}_{2}$ and altered poleward ocean heat flux specified in the atmospheric model simulations used as surface forcing to the ocean model. These results suggest that Early Eocene climate change relative to the present-day may have been the result of circulation change due to plate tectonics as well as atmospheric changes due to increased $\mathrm{CO}_{2}$.

The purpose of this presentation is to illustrate how globally distributed paleontological, sedimentological and geochemical data is used to evaluate the quality of ocean general circulation model experiments. Mean annual and seasonal threedimensional temperature fields from Eocene ocean model simulations will be compared with paleotemperature calculations from $\delta^{18} \mathrm{O}$ measurements for Early Eocene cores from more than 35 Deep Sea Drilling Program and Ocean Drilling Program sites. The publication of oxygen isotope analyses for single species foraminifera samples allows the evaluation of model-predicted temperature fields for mixed layer, sub-thermocline and bottom ocean layers. The potential for using the model-predicted surface salinity field to calibrate the mixed-layer isotopic paleotemperature calculation will be considered. 